\title{
Abordagem prática de pesquisa em ecossaúde: teoria, métodos e aplicações
}

\author{
A practical approach to research in ecohealth: theory, methods, \\ and applications
}

\author{
Enfoque práctico de investigación en ecosalud: teoría, métodos y \\ aplicaciones
}

\begin{abstract}
ENFOQUES ECOSISTÉMICOS EN SALUD Y AMBIENTE: APORTES TEÓRICOS-METODOLÓGICOS DE UNA COMUNIDAD PRÁCTICA. Betancourt O, Mertens F, Parra M. Quito: Ediciones Abya-Yala; 2016. 296 p. ISBN 9789942-09-339-4.
\end{abstract}

doi: 10.1590/0102-311X00130618

Esta coletânea de textos foi organizada por Oscar Betancourt (Diretor da Fundação Saúde, Ambiente e Desenvolvimento - FUNSAD, Quito, Equador), Frédéric Mertens (Professor Adjunto no Centro de Desenvolvimento Sustentável, Universidade de Brasília, Brasília, Brasil) e Manuel Parra (Comunidade Prática sobre o Enfoque Ecossistêmico em Saúde Humana na América Latina e Canadá - CoPEH LAC, Chile). Reúne textos que têm em comum o objetivo de mostrar os fundamentos teóricos, conceitos e metodologias do enfoque ecossistêmico em saúde humana (ecossaúde).

Os autores fazem parte da rede CoPEH, um grupo de troca de conhecimentos e experiências e de desenvolvimento de capacidades sobre as condições sociais, econômicas e ambientais que interferem na saúde de populações da América Latina e Caribe, e é apoiada pelo Centro Internacional de Pesquisa e Desenvolvimento (IDRC). Mais informações sobre a rede estão no website (http://www.copehlac.una.ac.cr). A equipe que forma essa rede é interdisciplinar e se organiza em nós regionais. Ela se dedica ao estudo dos problemas ambientais que afetam a saúde de populações vulneráveis. Cada grupo de pesquisa (nó), vinculado a diferentes países da América Latina, tem o seu plano de trabalho dentro da rede. Com frequência, os grupos se reúnem para compartilhar as experiências regionais e para elaborar planos em conjunto para a difusão de informações sobre o enfoque ecossistêmico em saúde humana. O livro resenhado foi fruto de diversos encontros desses grupos e da necessidade de ter um material bibliográfico elaborado pelos próprios estudiosos da América Latina atuantes nessa área, com o objetivo de fortalecer as investigações sobre esse tema tão importante (e presente).

Vale mencionar que os textos reunidos neste volume discutem a problemática de saúde associada às condições de vida e de trabalho precários aos quais estão submetidas muitas populações. Essas condições estão ligadas à presença de indústrias extrativas de minério, de plantações agrícolas em grande escala, e do desmatamento associado ao surgimento de novas paisagens que favorecem a proliferação de novos vetores e doenças (como a malária, a dengue e a doença de Chagas).

De modo global, todas as interferências humanas numa parte do meio natural modificam a cadeia alimentar, introduzem novos contaminantes ou vetores e, por conseguinte, afetam as pessoas residentes. O capítulo introdutório 
discute o contraste entre a riqueza natural da América Latina e o padrão de desigualdade social que prevalece nos seus diversos países. De fato, a América Latina é a região mais desigual do planeta, como afirmam Moreira et al. nesse primeiro capítulo. Além disso, a urbanização da região é crescente: $80 \%$ da população latino-americana reside em cidades, cujo desenho é em grande parte caótico, com limitado acesso à água e ao saneamento básico.

Betancourt et al. (no capítulo 4) mencionam que o estado de saúde das populações está diretamente relacionado a direitos básicos como nutrição adequada, moradia digna, o acesso à educação e a programas de saúde. A crescente degradação ambiental, consequência da prevalência de leis de mercado e de interesses de grupos econômicos, também fragiliza a saúde de vários grupos sociais. Na América Latina, os mesmos autores destacam o surgimento de novas abordagens que consideram a saúde desde uma perspectiva integral. Para tanto, é necessário um esforço para entender os determinantes sociais de saúde, que incluem a pobreza, a inequidade, a marginalização e a exclusão social.

Em contraposição ao pensamento convencional sobre saúde, os autores da obra enfatizam a necessidade de concepções holísticas, associadas ao enfoque ecossistêmico em saúde humana (ecossaúde). Essas concepções são desenvolvidas por Forget \& Lebel ${ }^{1}$ e posteriormente por Charron ${ }^{2}$. Esses autores são referência no campo da ecossaúde e permeiam muitos capítulos do livro. A ecossaúde propõe soluções integradoras para as problemáticas de saúde ligadas ao manejo do ecossistema. $\mathrm{O}$ ambiente natural, nesse contexto, não é isolado do ser humano. A ecossaúde leva em conta as relações complexas e uma integração entre as dinâmicas biológicas, químicas, da vida terrestre e aquática, conforme mencionam Betancourt et al. (capítulo 4). Essa abordagem está alicerçada nos pilares da transdisciplinaridade (capítulo 5), participação social (capítulo 6) e equidade social e de gênero (capítulo 7).

A transdiciplinaridade, tratada no capítulo 5 por Mendez et al., implica a visão integrada dos problemas de saúde e os desequilíbrios dos ecossistemas. Ela exige o envolvimento de pesquisadores e especialistas, membros das comunidades e tomadores de decisão para que se consiga lidar com a complexidade de interações dos componentes ambientais, sociais e de saúde. Betancourt \& Valle, no capítulo 2, abordam a teoria geral dos sistemas de Bertalanffy ${ }^{3}$, aplicada a uma atuação transdisciplinar. Afirmam que uma abordagem integradora, focada nas relações entre os conjuntos de conhecimentos que emergem da pesquisa em ecossaúde, é um espaço frutífero para a comunicação entre os pesquisadores e suas especialidades, entre saberes científicos e saberes tradicionais.

A participação social, relatada por Tirelli et al. no capítulo 6, mais que um conceito, é um processo. Por trás da busca pela participação há o engajamento político dos pesquisadores e o compromisso com a transformação social. Esses processos dão condições para lidar com a realidade local, problematizá-la e, por conseguinte, fomentar a autonomia e a democratização da sociedade. A equidade social e de gênero, discutida no capítulo 8 por Arenas et al., reconhece a equidade como um direito humano pautado na ética e na justiça social. A inequidade contribui para a restrição a oportunidades e está associada a grupos historicamente excluídos social e economicamente, em razão da sua classe social, étnica ou de gênero.

O livro, na sua última parte, traz modelos práticos de gestão de conhecimento. Santandreu (capítulo 9) apresenta a gestão do conhecimento como uma forma de aprendizagem e troca dentro dos projetos de pesquisa. Philibert (capítulo 10) aborda o método de "ciclos" de conhecimento, com a recapitulação das fases anteriores da pesquisa, para avaliar a viabilidade de cada etapa, as conexões entre elas e a possibilidade de melhoras.

É importante mencionar que a abordagem em ecossaúde tem enfoque na prevenção em saúde, mais do que na atenção à resolução das enfermidades. Procura entender quais são os determinantes sociais e ambientais da saúde das pessoas 
e dos ecossistemas. O capítulo 7 propõe meios de incorporação dos princípios da ecossaúde tanto para grupos não acadêmicos (líderes comunitários, delegados sindicais) quanto no currículo das universidades. Nas universidades, é importante destacar que a formação dos profissionais não contribui com a integração disciplinar. Como explicitam, a formação universitária latino-americana ainda segue modelos disciplinares, hiperespecializados, que dificultam tanto o trabalho em equipe quanto a formação de visões holísticas na construção do conhecimento. Mas existem experiências positivas que podem servir como modelos. Os autores indicam a necessidade de trabalhar as estratégias de ensino pautadas na resolução de problemas da realidade.

Este livro reúne os fundamentos necessários para pensar as problemáticas de saúde e ambiente na América Latina. É um bom direcionador para estudantes, pesquisadores e interessados na temática da saúde e ambiente. Traz os principais autores que são pioneiros na ecossaúde e inclui contribuições originais tanto teóricas quanto metodológicas de pesquisadores envolvidos na rede CoPEH LAC. Ressalta-se o imenso esforço exigido para a realização do livro, pois o grupo está espalhado por diversos países da América Latina e Canadá. No entanto, a distância e a dificuldade de comunicação não foram empecilhos para a realização da obra.

Ligia Valadão 1,2

1 Universidade Federal do Oeste do Pará, Santarém, Brasil.

2 Universidade de Brasília, Brasília, Brasil.

ligiameres@gmail.com

1. Charron D. Ecohealth research in practice: innovative applications of an ecosystem approach to health. Ottawa: International Development Research Centre; 2012.

2. Forget G, Lebel J. An ecosystem approach to human health. Int J Occup Environ Health 2001; 7(2 Suppl):S3-38

3. Bertalanffy LV. Teoria geral dos sistemas. Petrópolis: Editora Vozes; 1973. 